BENM 2021

International Scientific and Practical Conference "Biotechnology, Ecology, Nature Management"

\title{
HISTOCHEMICAL AND MORPHOMETRIC PECULIARITIES IN PHILODINA ROSEOLA RITS IMPORTANT FOR GERONTOLOGICAL STUDIES
}

\author{
L. I. Buchkova (a)*, S. V. Smorodinskaya (b), Yu. G. Simakov (c), K. F. Gross (d) \\ *Corresponding author
}

(a) K.G. Razumovsky Moscow State University of Technologies and Management (the First Cossack University, 73, Zemlyanoy Val str., Moscow, Russia, larabychkova@mail.ru

(b) K.G. Razumovsky Moscow State University of Technologies and Management (the First Cossack University, 73, Zemlyanoy Val str., Moscow, Russia, s.smorodinskaya@mgutm.ru

(c) K.G. Razumovsky Moscow State University of Technologies and Management (the First Cossack University, 73, Zemlyanoy Val str., Moscow, Russia, usimakov@yandex.ru

(d) K.G. Razumovsky Moscow State University of Technologies and Management (the First Cossack University, 73, Zemlyanoy Val str., Moscow, Russia, justinnennessey96@mail.com

\begin{abstract}
To solve the problems of aging of the body, it is necessary to trace how life span connected with the growth and differentiation of cells reproduction and genetic apparatus. To solve this problem, we have selected the rotifers Philodina roseola, which have endogenous aging and a very short lifespan. The distribution of DNA and RNA in organs of Philodina roseola rotifers taken from activated sludge and raw cultures was studied by histochemical methods. It has been shown that these microscopic animals contain DNA only in certain cellular and syncytial structures, while RNA is detected in the cytoplasm of most cells. The disappearance of nuclear chromatin with DNA in most organs during ontogenesis suggests that the lifespan of rotifers is limited by the lifespan of messenger RNA. In addition, the growth mechanism and the aging process in rotifers born from young and old individuals have been studied morphometrically. This study makes the rotifer Philodina roseola an irreplaceable object for gerontological research.
\end{abstract}

2672-8575 ㄷ 2022 Published by European Publisher.

Keywords: DNA, gerontology, nuclear chromatin, Philodina roseola, RNA, rotifer 


\section{Introduction}

The rotifers Philodina roseola Ehrenberg, belonging to the order Bdelloida, reproduce by parthenogenetic means. Rotifers have a short lifespan (Keke et al., 2017; Troen, 2003), and their cells do not divide in adulthood (Clément, 1977). In rotifers, endogenous aging, in this respect, they model the aging type in humans and mammals. At the same time, a gerontologist can observe the aging of an entire generation for a month, which is not feasible in long-lived animal species. It becomes possible to use this object in descriptive and experimental works for a shorter period in the study of aging. In essence, the life of this microscopic multicellular animal is determined by the life span of individual cells after their division ends in the embryonic period. The majority of rotifer organs are represented by syncytial structures formed in the process of fusion of cells that were originally divided during the embryonic period (Becks \& Agrawal, 2010).

For gerontological studies, it is also important that the filodina rotifers belong to the order Bdelloida in which parthenogenetic reproduction. Consequently, all females have approximately the same life cycle and produce the same genetic clones, while in rotifers from the order Monogononta, the lifespan and aging processes in myctic and amyctic females differ (Nikiforov-Nikishin et al., 2020; Song \& Lee, 2017).

Rotifers Philodina roseola are found in wastewater, sometimes quite toxic, as well as in activated sludge of aerotanks and biofilm of aerofilters and serve as one of the indicators of the treatment plant operation (Gribble, 2021). The ability of rotifers to live in certain zones of saprobity (Simakov, 1974) and to be present in wastewater containing harmful substances, apparently, indicates the originality of the metabolic processes in these organisms.

Morphometric methods were used to measure body length growth in rotifers filodin and their offspring, depending on the age of mothers and life expectancy. In this case, the distribution of DNA and RNA in cells was also investigated in the offspring to identify the state of the genetic material at different periods of life, depending on cell differentiation.

\section{Problem Statement}

All of the above prompted us to study the features of the distribution of DNA and RNA in the cellular and syncytial structures of organs in mothers and their offspring for their subsequent use in gerontological studies.

\section{Purpose of the Study}

The aim of the work was to find the most indicative parameters of cell differentiation, reproduction and aging in rotifers filodin, which can be used to solve the problems of aging in the organism. 


\section{Research Methods}

The rotifer Philodina roseola was selected with a thinly drawn Pasteur pipette from activated sludge and raw cultures (Clément, 1977). After pressing with a cover glass and freezing on a thermoelectric table, the cover glass was torn off, and the rotifer, as quickly as possible, was placed on a glass slide in a frozen state in a mixture of alcohol - acetone (1:1) for fixation (Sarkisov \& Perov, 1996). This method makes it possible to obtain a rotifer glued to a microscope slide, spread over it for $10-15$ $\mu \mathrm{m}$, which can be moved through the medium of histological wiring together with the slide. Then the fixed material was passed through histological wiring to water and stained for DNA and RNA with methyl green-pyronine (Lojda et al., 2012). In parallel, DNA was detected by the Völgen reaction; part of the material was stained for DNA and RNA with acridine orange (Ehrenpreis, 1971). Permanent preparations during the first two reactions were prepared by pouring into Canadian balsam, and for luminescence microscopy, the preparations were embedded in non-fluorescent immersion oil. For general morphological control, preparations were stained with Ehrlich hematoxylin (Fontaneto \& Jondelius, 2011).

A total of 126 total preparations of rotifers stained with methyl green-pyronine were made and studied; 90 preparations stained according to Feulgen; 57 preparations stained for DNA and RNA with acridine orange, and 50 preparations stained with hematoxylin. The preparations obtained were examined using an MPI-5 polarization-interference microscope, an ML-3 fluorescent microscope and a video setup, including: a digital camera based on the Olympus 840 microscope and a computer.

Morphometric studies were carried out on adult rotifers and their offspring. The change in body length of rotifers was studied during the life cycle. The measurement was carried out from the cilia of the rotary apparatus to the ends of the toes using an object-micrometer with a microscope magnification of 40 $\mathrm{x}$ 15. Preliminarily, the division value of the eyepiece-micrometer at this magnification was determined using an object-micrometer. In life, rotifers are constantly in motion, which complicates the measurement of their parameters, therefore, the measurement of body length was carried out on fixed preparations, taking into account that before freezing. Filodines that did not have a shell were completely stretched under the cover glass, and the freezing process on a thermoelectric table did not lead to the compression of their body.

To obtain offspring in the form of a clone, we used the property of filodin rotifers discovered by us to lay eggs to the end of a coverslip placed on the bottom of a bottle with $10 \mathrm{ml}$ of culture solution containing bacteria for feeding rotifers. A female placed in such a weighing bottle overnight lays 5 to 8 eggs in one row to the end of the coverslip. Thus, it is possible to find laid eggs at the bottom of a glass container immediately above the microscope and monitor the development of rotifers. When removing an adult, you can get a clone of genetically the same offspring. This method allows you to check. How life expectancy and aging are related in offspring received from young and old mothers. This is very important for gerontological research and makes it possible to study the growth and aging processes in one generation of filodin in 27 days. 


\section{Findings}

In Methyl green - pyronine staining specifically differentiates biological structures containing DNA (green) and RNA (red). The study of total preparations of rotifers Philodina roseola, stained by the Brachet method, showed that the cytoplasm of all cells is stained with a faint red color, but the intensity of the staining in different organs varies sharply. The most intense staining is the syncytium of the vitelline, where, apparently, the amount of RNA is ten times greater than in other organs. A high RNA content can also be noted in growing oocytes. The second place in terms of the intensity of staining on RNA is taken by the cerebral ganglion of the rotifer, followed by the sticky glands of the leg, in which the RNA content is higher than in other organs. The hypodermis, digestive and excretory systems are painted in a pale pink color, which indicates the presence of a small amount of RNA in them.

At first glance, on preparations stained according to Feulgen, it is difficult to detect a bluish-purple color corresponding to the sites of DNA localization in rotifer organs. However, a detailed study reveals in the ovary 21-22 stained nuclei with a size of about 2 microns. The same greenish tint is found on the periphery of the large nuclei of the vitelline syncytium. The nuclei themselves are colored yellow with a fine reticular structure in red, which may indicate the presence of RNA inside the vitelline nuclei. The rest of the syncytial and cellular organs are colored only reddish.

A specific reaction to DNA no Voelgen showed that the ovarian nuclei are stained most intensely. DNA is very weakly detected at the periphery of the nuclei of the vitelline syncytium. Unlike staining with methyl green - pyronine, the Völgen reaction makes it possible to detect DNA in the nuclei of cells of the cerebral ganglion of rotifers. In this case, the nuclei are very weakly colored. By the Völgen reaction, DNA was also detected in the nuclei of the glue gland cells of the leg, but the staining was as weak as the staining of the nerve cells of the cerebral ganglion. In total, only a few bluish-purple islets in the organs described above are visible on the permanent Völgen stain. The rest, most of the rotifer body, is colorless, which indicates the absence of DNA in a number of cells.

The identification of nucleic acids using acridine orange on total preparations and examination of the preparations in the field of view of a luminescent microscope confirmed the localization sites of DNA and RNA in various organs of rotifers. The cytoplasm of the vitelline and the cytoplasm of growing oocytes had the highest red luminescence, which indicates a high content of RNA in them. Green luminescence was observed in small nuclei of ovarian cells and in the periphery of large nuclei of vitelline cells. The nuclei of the cells of the cerebral ganglion and adhesive glands of the leg also exhibit weak luminescence, which indicates the presence of DNA in them. All other tissues emit a faint reddish color, indicating the presence of a small amount of RNA, evenly distributed over the cytoplasm of cells.

In figure 1 shows a diagram of the distribution of DNA and RNA in various organs of the rotifer, obtained based on summation of the data of all histochemical research methods used in this work. Thus, the presented diagram of the localization of nucleic acids in the organism of Philodina roseola on the 4th day of the life cycle more fully reflects the picture in comparison with photographs, and includes the results. Obtained at once by three histochemical methods.

Morphometric methods in this work have shown that growth in rotifers of filodin occurs before the onset of aging processes. Individuals hatched from eggs grow for 3 days, and then they become sexually 
mature and begin to lay eggs themselves. Their active life period also lasts up to 18 days, but less intensively, then growth stops and the aging period begins, which lasts more than a week. During aging, rotifers develop wrinkles on the body, fat granules accumulate in the cytoplasm, and dark pigment is deposited in the intestines and digestive glands. Swimming is replaced by crawling along the bottom of the vessel. On average, after 27 days, the life of Philodina roseola rotifers ends. The data obtained on the change in body length in rotifers during the life cycle are shown in Figure 2.

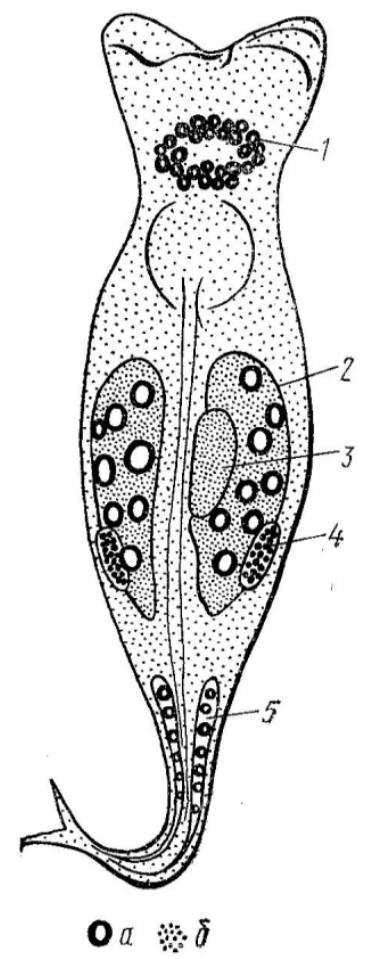

Figure 1. Distribution of DNA (a) and RNA (b) in the cells of various organs of the rotifer: 1 - cerebral ganglion, 2 - vitelline, 3 - growing oocyte, 4 - ovary, 5 - leg glands

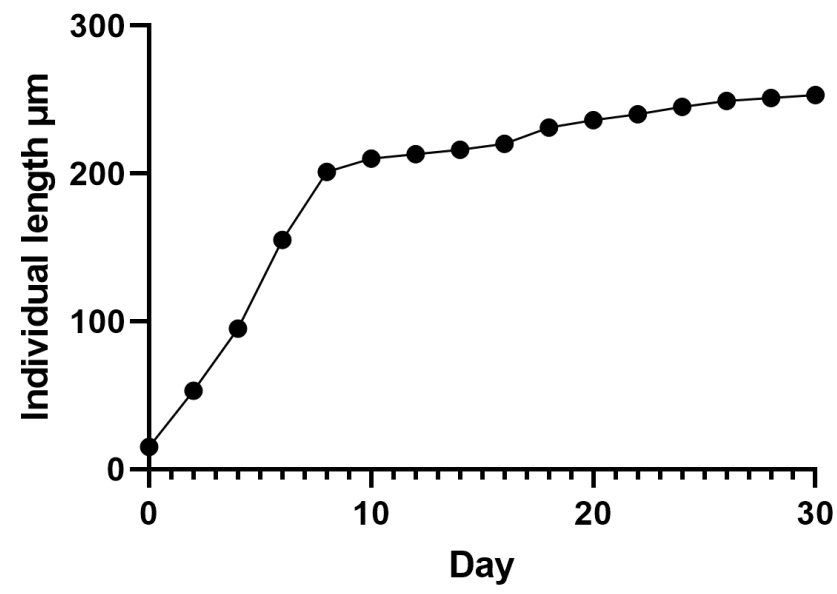

Figure 2. Increase in body length of the rotifer Philodina roseola during its life cycle 
The presented graph (Figure 2) shows that the growth of the rotifer body goes along a parabola, before the onset of aging. With the beginning of the structure, the growth of the body stops. At the same time, reproduction is disrupted: there are fewer oogonia in the ovary, and the process of oogenesis fades away. On the 18th day, rotifers still lay eggs, the development of which we have followed in this work.

To address the question of how the age of mothers affects the development, life expectancy and aging in offspring obtained from young and old females, observation was also carried out.

It was revealed that the offspring obtained from young females at the age of 6 days develops in a manner similar to that shown in Figure 2. In the offspring obtained from 10-day-old females, there is already a decrease in life and earlier aging. The offspring obtained from old females at the age of 18 days die even earlier. At the same time, the initial development of rotifers obtained from old females is accelerated, and they complete their growth earlier than the offspring obtained from young females. The regularities of the life expectancy of offspring obtained from young and old females are shown in Figure 3.

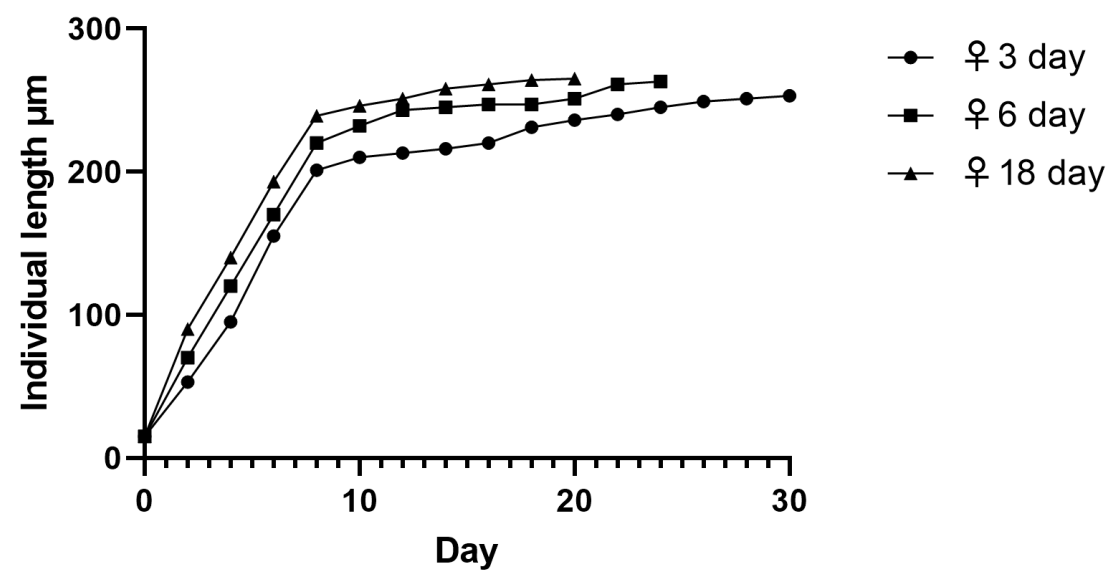

Figure 3. Influence of mother's age in rotifers Philodina roseola on growth, aging and life expectancy in offspring (the legend gives the age of mothers from which offspring are obtained: upper line 18 days; middle 10 days; lower offspring from 6 day old female)

Histochemical studies of the distribution of nucleic acids in females of different ages show that in old individuals, the staining of the cytoplasm for RNA begins to fall on the 18th day of life. Moreover, in old individuals, the cytoplasm is almost not stained for DNA, but deposits of small fatty drops are noted in it. Therefore, with the cessation of growth and the onset of aging, the synthesis of mRNA most likely stops. In offspring received from old mothers, the process of RNA synthesis stops 2 to 4 days earlier. Than the offspring obtained from young mososov. This is evidenced by the faded RNA staining of the cytoplasm of cells before the onset of the aging process in rotifers grown from eggs laid by old mothers.

Thus, DNA is contained only in individual organs of Philodina roseola and in insignificant amounts. Most likely. After the completion of embryonic development, DNA resorption occurs. The highest content of RNA was found in the gonads, in particular, in the vitelline, which feeds rapidly growing oocytes during the rotifers' reproduction period.

The fact that DNA is not detected in a number of organs may indicate resorption of nuclear material after the cessation of cell division in rotifers. Apparently, further protein synthesis. When cells 
stop dividing and only increase in size and occurs only due to mRNA accumulated in the cytoplasm during embryonic development. If this is the case, then the wear and tear of RNA molecules and the time of their failure determines the lifespan of the rotifer. Essentially, a rotifer lives as long as mRNA is stored. Apparently, the aging mechanism of this microscopic organism is similar to the aging of such cellular structures as non-nuclear erythrocytes of mammals or lens fibers, where protein synthesis occurs in the absence of gene expression, and in the lens of the eye due to long-lived mRNA (Kotikova et al., 2005). Such processes take place in somatic cells. While in germ cells, where rapid growth of oocytes is required, gene expression lasts much longer. Therefore, old rotifers can still lay eggs, although it often happens that they turn out to be ugly, and the offspring obtained from such eggs are eliminated by shortening the life span, which is also noted by a number of authors (Clément, 1977; Troen, 2003).

The studies carried out made it possible to establish that RNA is contained in those organs of rotifers that most actively synthesize secretions or ensure rapid cell growth in the reproductive system. RNA is especially intensely detected in the vitelline feeding oocytes, while DNA is present in the nuclei of the vitelline cells. It is found on the periphery of the large nuclei of the vitelline. The peripheral arrangement of DNA is a rare phenomenon in nuclear cytochemistry.

True, for quite a long time D. Cheyenne (according to Gladyshev et al., 2008) during microspectrophotometry of Vicia faba cells in vivo managed to observe the release of DNA into the cytoplasm during the interphase period. At the same time, the nucleus itself weakly absorbed ultraviolet rays and, apparently, the nucleus was devoid of a significant part of DNA. The peripheral arrangement of DNA in the nuclei of the vitelline of rotifers that we identified is due either to the rapid fixation of a small object, in which DNA does not have time to return from the syncytial cytoplasm to the nucleus, and then Cheyen's conclusions are confirmed. Due to the introduction of an artifact in the process of fixation during the manufacture of cytochemical preparations. In both cases, additional verification of the results obtained is required.

DNA is also detected in the cerebral ganglion of the rotifer, which indicates an increased functional load of this organ and the need for RNA synthesis for the memory mechanism to function (Boschetti et al., 2011). In the nervous system, it is possible that neurosecretory cells located near the cerebral ganglion work very hard. The increased metabolism makes it necessary to replenish the synthesis of m-RNA in cells similar to the neuroglia of higher animals, in which a long-term mash is stored. Therefore, DNA can be detected not only in neurons, but also in neurosecretory cells adjacent to the cerebral ganglion. Neurosecretory cells in close contact with the cerebral ganglion have been found not only in Philodina roseola, but also in other rotifer species (Hespeels et al., 2014); it is possible that this feature is inherent in all types of rotifers.

Parthenogenetic reproduction of rotifers Philodina roseola and a peculiar distribution of nucleic acids, especially DNA in their organs, makes this object very convenient for solving various hypotheses related to the aging mechanism of not only rotifers, but also other multicellular animals, including humans.

Particular attention in this study is paid to the work of the hereditary apparatus in old and young individuals. First, it was shown that the amount of RNA in somatic cells of filodin decreases with age, therefore, the synthesis of enzymes and structural proteins stops. RNA synthesis can stop only after the 
expression of genes in DNA is complete. In this way. it turns out that the aging process and lifespan in rotifers are genetically programmed. For this reason, philodines represent a very convenient model in gerontology, which can be used to solve the problems of life extension and aging, since due to the lack of hybridization, each subsequent generation will be genetically homogeneous. Although the latter statement is questioned by a number of researchers who believe that, there is a horizontal transfer of genetic material in filodin (Gribble, 2021).

Secondly, biologists believe that one of the main signs of aging is the extinction of the ability to reproduce. Indeed, in some species of rotifers. This is exactly what happens, the individual dies after the supply of oocytes in the gonads is used up (Clément, 1977). The same examples can be found in other animal species (Troen, 2003). However, in rotifers, filodin, from the beginning of aging and the completion of growth, the sexual function does not stop. In this respect, they are somewhat reminiscent of mammals, including humans. Therefore, it becomes possible to answer the question. How does the age of mothers affect their offspring?

This work shows that this influence can be assessed as unfavorable. Recently, especially in Western countries, women have a tendency to have children at a later age. Therefore, if, established on rotifers, the mechanism of negative influence on life expectancy and early aging to some extent manifests itself in humans, every effort should be made to exclude it and recommend women to have children under 30-35 years old. As we can see in rotifers, this leads to a reduction in the life of the offspring and to earlier aging. In wild animals, this will not manifest itself, since they still have competition, and the old sexual partner is less likely to produce offspring in rotifers with parthenogenetic development, where there is no sexual competition, in general, old individuals give birth to offspring, which is eliminated by the special structure of the hereditary apparatus.

It is impossible, of course, when studying the distribution of DNA in rotifers and the mechanisms of their aging, for completely transfer the revealed properties to higher animals. Many features of the hereditary apparatus of rotifers will be inherent only to them. This is evidenced by the ability of rotifers to withstand drying out and fall into suspended animation, as well as withstand a higher content of toxic substances in wastewater. The genetic system of rotifers contains a reduced amount of DNA; therefore, the influence of harmful substances, especially mutagens, most likely affects the genetic apparatus to a lesser extent than in organisms containing an increased amount of DNA. Developing rotifers, in which cell differentiation, mitotic divisions, and fusion of cell structures into syncytial formations proceed at a rapid rate, form an organism that is more resistant to anthropogenic influences.

\section{Conclusion}

1. Cattle Philodina roseola, which are very easy to cultivate in laboratory conditions, can become a valuable gerontological object, since they exhibit endogenous senescence similar in their mechanisms to the aging of mammals.

2. The lifespan of the indicated rotifers takes no more than 27 days, therefore, for an experimenter investigating the mechanisms of aging and studying methods of life extension, rotifers can be an irreplaceable object on which one can trace the life of a whole generation in one month. 
3. Many questions related to cytodifferentiation and genetics of aging can be solved with the help of rotifers, since their body consists of a limited number of cells and grows until the aging period. With the cessation of growth after 18 days, the aging period begins, during which wrinkles appear on the rotifer on the body, fat is deposited, reproduction gradually stops, and swimming is replaced by crawling.

4. Revealed by histochemical methods that in most somatic cells of rotifers, DNA and RNA are reduced, and protein synthesis for growth occurs due to RNA preserved from the embryonic period. At the same time, the presence of DNA is noted in the reproductive system (in the ovary and vitelline) and RNA is synthesized in the process of oocyte formation. In addition to the reproductive system, DNA is stored in the nuclei of the cells of the cerebral ganglion of rotifers, which is associated with the work of memory mechanisms.

5. Installed that older mothers give birth to offspring with early aging and shorter life spans. At the same time, DNA and RNA, detected by histochemical methods, begin to decrease in the offspring of old mothers earlier than in rotifers obtained from young mothers.

\section{References}

Becks, L., \& Agrawal, A. F. (2010). Higher rates of sex evolve in spatially heterogeneous environments. Nature, 468(7320), 89-92. https://doi.org/10.1038/nature09449

Boschetti, C., Pouchkina-Stantcheva, N., Hoffmann, P., \& Tunnacliffe, A. (2011). Foreign genes and novel hydrophilic protein genes participate in the desiccation response of the bdelloid rotifer Adineta ricciae. Journal of Experimental Biology, 214(1), 59-68. https://doi.org/10.1242/jeb.050328

Clément, P. (1977). Ultrastructural research on rotifers. Arch. Hydrobiol. Beih, 8, 270-297.

Ehrenpreis, Y. G. (1971). The nucleus of a cancer cell. Riga.

Fontaneto, D., \& Jondelius, U. (2011). Broad taxonomic sampling of mitochondrial cytochrome c oxidase subunit I does not solve the relationships between Rotifera and Acanthocephala. Zoologischer Anzeiger. A Journal of Comparative Zoology, 250(1), 80-85. https://doi.org/10.1016/j.jcz.2010.11.005

Gladyshev, E. A., Meselson, M., \& Arkhipova, I. R. (2008). Massive horizontal gene transfer in bdelloid rotifers. Science, 320(5880), 1210-1213. https://doi.org/10.1126/science.1156407

Gribble, K. E. (2021). Brachionus rotifers as a model for investigating dietary and metabolic regulators of aging. Nutrition and Healthy Aging, (Preprint), 1-15. https://doi.org/10.3233/NHA-200104

Hespeels, B., Knapen, M., Hanot-Mambres, D., Heuskin, A. C., Pineux, F., Lucas, S., Koszul, R., \& Van Doninck, K. (2014). Gateway to genetic exchange? DNA double-strand breaks in the bdelloid rotifer A dineta vaga submitted to desiccation. Journal of evolutionary biology, 27(7), 1334-1345. https://doi.org/10.1111/jeb.12326

Keke, U. N., Arimoro, F. O., Ayanwale, A. V., \& Oghenemarho, I. A. (2017). Rotifer (Brachionus Calyciflorus) could compete favourably with Artemia nauplii as alternative starter for African Catfish (Clarias gariepinus). Applied Science Research Journal, 4(2), 41-58.

Kotikova, E. A., Raikova, O. I., Reuter, M., \& Gustafsson, M. K. (2005). Rotifer nervous system visualized by FMRFamide and 5-HT immunocytochemistry and confocal laser scanning microscopy. Hydrobiologia, 546(1), 239-248. https://doi.org/10.1007/s10750-005-4203-5

Lojda, Z., Gossrau, R., \& Schiebler, T. H. (2012). Enzyme histochemistry: a laboratory manual. Springer Science \& Business Media.

Nikiforov-Nikishin, A. L., Nikiforov-Nikishin, D. L., Kochetkov, N. I., \& Tatarenko, P. Y. (2020, August). Biocenosis of cold-water and warm-water biofilter in recirculating aquaculture system. In IOP Conference Series: Earth and Environmental Science (Vol. 548, No. 8, p. 082097). IOP Publishing. https://doi.org/10.1088/1755-1315/548/8/082097

Sarkisov, D. S., \& Perov, Y. L. (1996). Microscopic technique. Leadership. Medicine. 
Simakov, Y. G. (1974). A new method for fixing rotifers for morphological and histochemical studies. Zool. Zhurn, 53(4), 623-626. https://doi.org/10.1177/00220345740530031601

Song, M. O., \& Lee, C. H. (2017). A new and five rare bdelloids from Korea. Zootaxa, 4242(3), 529-547. https://doi.org/10.11646/zootaxa.4242.3.6

Troen, B. R. (2003). The biology of aging. Mount Sinai Journal of Medicine, 70(1), 3-22. 